\title{
Outcome Measures for Chronic Inflammatory Demyelinating Polyneuropathy in research: relevance and applicability to clinical practice.
}

\author{
Yusuf A. Rajabally, ${ }^{1,2}$ Farzad Fatehi ${ }^{3,4}$
}

1. School of Life and Health Sciences \& Aston Medical School, Aston University, Birmingham, U.K.

2. Regional Neuromuscular Service, University Hospitals Birmingham, Birmingham, U.K.

3. Shariati Hospital, Tehran University of Medical Sciences, Tehran, Iran.

4. Aix Marseille University, CNRS (UMR 7339), Centre de Résonance Magnétique Biologique et Médicale, Faculté de Médecine, 27 bd. J. Moulin, 13005 Marseille, France.

NEURODEGENERATIVE DISEASE MANAGEMENT: Review/Perspective Article

\section{REVISED VERSION R1}

Abstract: 114 words

Word Count: 2540 words

Correspondence to:

Yusuf A. Rajabally

School of Life and Health Sciences \& Aston Medical School,

Aston University,

Aston Triangle,

Birmingham B4 7ET, UK.

E-mail : y.rajabally@aston.ac.uk 


\begin{abstract}
.
Outcome measures are recommended in the management of chronic inflammatory demyelinating polyneuropathy (CIDP). Various scales have been proposed in recent years, some now commonly utilised in daily clinical practice. The available evidence base relies itself on randomised controlled trial data obtained over the past thirty years, with several studies using different primary and secondary outcomes. We here review the different outcome measures used in CIDP research in relation to those currently recommended for clinical management. We consider the evidence base for CIDP treatment from the primary and secondary outcomes used in these studies and attempt to assess how this may relate to current clinical practice of routine evaluation of treatment effects and long-term monitoring.
\end{abstract}




\section{Introduction.}

Accurate assessment of neurological function in patients with inflammatory neuropathies is critical to track disease severity over time, to provide evidence of disease relapse, and to detect clinical improvement following treatment with immunomodulatory agents [1].

In chronic inflammatory demyelinating polyneuropathy (CIDP), multiple clinical rating scales have been proposed and used in research, some also applied in clinical practice. Several randomised controlled trials (RCTs) have been conducted in CIDP over the past three decades. The outcomes used as primary and secondary end-points in these trials have however differed. These varying methodologies impact upon the clinical applicability of findings and the relevance of currently recommended and utilised scales in day-to-day practice. To what extent the previously conducted RCTs are helpful to inform clinicians in their practice, is, as a result, uncertain.

The main goal of this article was to review the different scales used in CIDP research constituting the existing evidence-base, in relation to those proposed for CIDP management today and to attempt to establish the relevance of the research data, as available, to clinical practice. 


\section{Methods.}

We considered the main published therapeutic RCTs performed to date, in CIDP between 1990 and 2019, in relation to the primary and secondary outcome measures utilised in these studies. The potential implications for the current therapeutic evidence base for these disorders were evaluated in relation to applicability in current clinical practice.

\section{Outcome Measures for CIDP.}

In the last fifty years, several outcome measures have been proposed for the different inflammatory neuropathies. A classical outcome measure remains the medical research council (MRC) scale for muscle power [2]. This scale, still widely used today, grades muscle power on a scale of 0 to 5 . However, in recent years, the validity of MRC grading using six levels ( 0 to 5 ) has been challenged and a new grading with only 4 levels has been proposed [3].

The Neuropathy Impairment Score consists of an assessment of motor strength, reflexes and sensory function resulting in a total score from 0 (normal) to a maximum of 244 [4].

Other proposed scales have evaluated disability rather than muscle strength or clinical examination findings. These include Rankin Disability Scale (RDS) [5], the Hughes Disability Scale (HDS) [6], the Guy's Neurological Disability Scale (GNDS) [7]. The latter, used primarily in patients with multiple sclerosis, was adapted into the Inflammatory Neuropathy Cause and Treatment scale (INCAT) scale, (Hughes 2001, [8] which also consisted of a separate sensory component in the INCAT sensory scale [9]. The INCAT scale, which also became known as the "Overall Disease Disability Scale" or "ODSS", subsequently led to development of the "Overall Neuropathy Limitation Scale", or "ONLS" [10]. The Rotterdam Handicap Scale (RHS) [8] was devised as a more extensive disability 
evaluation measure. More recently, the Rasch-Built Overall Disability Scale [11], based on Rasch-transformation of functional measures, was derived by an international collaborative group, offering a wider assessment of disability. Also recently, grip strength as measured by a Martin Vigorimeter or a Jamar dynamometer has been found to correlate well with disability and strength measures and has hence been proposed as a quick and reliable outcome measure in inflammatory neuropathies $[12,13]$. Other scales used have been walking measures, such as the timed 10-metre walk and the 6-minute walk test. Detailed myometry finally has been used in evaluation of patients with various neuropathies including CIDP in clinical observational studies as well as trials, requiring complex and widely unavailable equipment [14].

\section{Overview of Outcome Measures used in RCTs in CIDP.}

Table 1. summarises the outcome measures used in CIDP research in the main RCTs considered. Table 2. details the type of evaluation offered by each. Considering the main immunoglobulin RCTs in CIDP, 2 used the NDS as primary outcome measure. Neither used a clinical secondary outcome. The study by Dyck et al. [15] compared intravenous immunoglobulins (IVIg) to plasma exchange (PLEX). The study by Hahn et al. [16] compared IVIg to placebo. Another study [17] comparing IVIg versus placebo, used the HDS as primary outcome measure and the Average Muscle Score (AMS), as secondary outcome. A further study, also comparing IVIg to placebo, used the Rankin scale as primary and the MRC sum score as secondary outcome measure [18]. Thompson et al. [19] in their study comparing IVIg and placebo used the Hammersmith Motor Ability Scale (HMAS) as primary outcome and several secondary outcomes, including timed 10-metre walk, MRC sum score, myometry and 9-hole peg test. In a study comparing IVIg to prednisolone, Hughes et al. [20] used as primary outcome the INCAT scale, with also multiple secondary clinical outcomes including timed 10-metre walk, MRC sum score, grip strength, 9-hole peg test, modified 
Rankin scale (mRS) and RHS. The ICE Study [21] comparing IVIg to placebo in a responseconditional cross-over design study over 24 weeks utilised the INCAT scale as primary outcome and grip strength as secondary outcome. The Randomised Methotrexate CIDP (RMC) Study evaluating the usefulness of methotrexate in reducing immunoglobulin or steroid requirements, used the ONLS [22]. A RCT comparing 2 different IVIg products [23], used the ODSS as primary outcome with MRC sum score and grip strength as secondary clinical outcomes. The Italian study comparing IVIg to intravenous methylprednisolone (IMC Trial), defined within the primary outcome, ineffectiveness, by deterioration of ONLS and mRS scores [24]. A French RCT of IVIg versus oral prednisolone (Camdessanché et al., 2015) used the INCAT scale as primary outcome [25]. Subcutaneous immunoglobulin was trialled as first-line therapy versus IVIg in treatment-naïve CIDP [26], with change in isokinetic dynamometry as primary outcome measure. Clinical secondary outcomes used were MRC sum score, Jamar grip dynamometry, 9-hole peg test, 40 metre walk test and ODSS. An openlabel Japanese 52-week phase III trial for its part, used the adjusted INCAT scale [27]. The most recent RCT of immunoglobulins in CIDP was the PATH study, which compared 2 SCIg dosages versus placebo [28], using the adjusted form of the INCAT scale as primary outcome. Clinical secondary outcomes were the grip strength, MRC sum score and I-RODS.

Steroids were compared to placebo in a trial published in 1982 [29] which used the NIS as primary outcome. Comparison of daily versus monthly high-dose steroids was performed in the PREDICT Trial [30] using as primary outcome the Rivermead Mobility Index (RMI) and the INCAT disability scale. Both RCTs of PLEX versus sham PLEX [31,32] used the NIS as primary outcome. 


\section{Concept of Minimal clinically important difference (MCID).}

In addition to statistical significance, the MCID is an important notion used to determine whether a medical intervention improves outcomes, as perceived by patients themselves [33]. The MCID has been defined as the "smallest difference in score in the domain of interest which patients perceive as beneficial and which would mandate, in the absence of troublesome side effects and excessive cost, a change in the patient's management" or, in other words, the lowest threshold for change that is important to or valued by the treated patient [34, 35]. The concept of MCID is crucial in understanding outcomes [35]. The concept has been applied retrospectively to CIDP studies post-hoc, after derivation by anchor-based and distribution methods. In the case of the INCAT scale, which uses integer values, the MCID has been found of $<1$, and has, as a result, been rounded up to $1[36,37]$. Similarly, the MCID for the MRC sum score has, post-hoc, previously been rounded up to 4 [37]. In addition, calculated MCIDs have been determined for grip strength [37], and applied in retrospect [37].

MCIDs have not been studied, to our knowledge, in relation to other previously used scales, particularly NIS/NDS, Rankin scale, HDS, although have been suggested recently for the 6minute walk distance test in CIDP [38]. For the I-RODS, MCIDs have been derived but so far, not implemented in therapeutic trials. Application of the MCID concept may alter the conclusions of CIDP research, in relation to genuine, patient-experienced and patient-relevant, clinical effectiveness of intervention. This has been to date, to our knowledge, only applied post-hoc to the ICE Study [37]. With regards to the INCAT disability scale, results were identical with anchor-based and distribution-based methods which both yielded MCIDs $<1$, whereas results for grip strength differed.

Application of research data to outcome measure use in daily practice. 
The initial therapeutic studies in CIDP, performed between 1994 and 2001 used primarily motor scales with the NIS/NDS as well as HDS, and in one case the HMDS. The Rankin scale was used in one. Many studies used the MRCSS as secondary outcome. These studies provided the initial basis for subsequent research. They are not however directly applicable to today's practice, as treatment decisions with regards to the individual functional benefit expected in such a heterogeneous disorder, is now widely accepted as necessarily requiring consideration of specific disabilities that may be reversible. Accepting the results of these initial studies as forming part of the evidence base requires the scales used as being appropriate for CIDP. This has however been challenged and led to the development of new scales.

Since 2001, the INCAT and ONLS have been used in multiple studies, as primary outcome. Most of the more recent evidence-base for immunomodulatory therapies rely on these studies. That significant comparative results were demonstrated post-hoc between treated and placebo groups in the ICE Study, considering the MCID [37], is of practical clinical application, as indicates importance of the results obtained in direct relevance to patient-perceived benefit, albeit with the intrinsic limitations of the utilised scale.

Rasch-built scales have been advocated to overcome the limitations and the variable importance of different items on traditional scales as well as differential weighing, making their validity questionable. A Rasch-built linear weighted scale specifically for GBS and CIDP was hence developed with transformation of raw scores to a centile metric, which was tested for reliability and validated. This scale, the "I-RODS" has since been recommended for use in research and is commonly used in clinical practice in many centres. Review of the available, including recent evidence base for treatment of CIDP, does not however provide the basis from research data, for straightforward clinical application. As such, despite publication of the I-RODS in 2011, only the last RCT of SCIg [28], used the new scale and 
only as secondary outcome measure. The mean difference in centile score of the I-RODS between high-dose SCIg and placebo groups was of 5, which in terms of raw score represents variable changes from 0 (at the extremities of the scale) to a maximum of 4 raw points (applicable between $47 \%$ and $43 \%$ exclusively, and lower at all other possible starting points). Although significant, the mean difference in change of centile I-RODS scores between high and low-dose SCIg groups was only of 2, corresponding to between 0 to 2 raw points. In terms of clinical significance, and considering raw scores, these statistical differences of mean are below previously published MCIDs for the scale.

Application of research into clinical practice ideally, first requires that meaningful clinically relevant scales are used, and that significantly greater numbers of responders are shown to attain MCID cut-offs in treated versus placebo groups. The former requirement has been debated for the INCAT/ODSS/ONLS but these scales have remained in preference to all others as primary outcome up till now. The latter requirement has been shown to be fulfilled only, to date, post-hoc, for the ICE Study. However, and importantly, if the INCAT scale is inadequate, the significance of reaching its MCID becomes highly uncertain. Similarly, it may be argued that the application of the MCID concept is irrelevant for the MRC sum score, in view of its poor reliability, as has been suggested [11].

In daily clinical practice, the MRCSS, as an exclusive motor evaluation, offers an easily applicable tool, although its lack of functional relevance is a clear issue. The intrinsic limitations of the MRC grading are also of obvious concern with regards to use for therapeutic decisions REF Van Houtte no.3 et PAS 39!! [39]. The INCAT/ONLS scales offer the significant advantage of rapid evaluation, although are limited by inadequacy for assessment of proximal arm function-related and stamina-related tasks REF Breiner no.1 et PAS 40!! [40]. Grip strength is a very attractive option for clinical practice, quick and easy to implement and correlating well with general disability. However, complete confidence in the 
validity of this tool is necessarily dampened by the several probable existing covariates, including depression [41]. The I-RODS presents the advantage of wide evaluation although the lack of validation across different populations as well as the wide diversity of CIDP as a clinical entity makes it of uncertain value for all patients.

Unfortunately, these many complexities are not considered in the advice and guidance provided by existing guidelines and national bodies to clinicians, with regards to clinical monitoring. Although the limitations of the available data and evidence restricts the detail and accuracy of any possible formulated directives, it would be desirable that these are themselves evidence-based. There appears to be a clear lack of evidence on the relevance outcome measures in CIDP as used in research, thereby raising doubt on the methods advocated and used in daily practice.

\section{Conclusion.}

Despite advances in the availability of newer disability outcome measures in recent years as well as enhancement of knowledge about and awareness of the importance of actual clinical relevance to affected patients, clinical practice in CIDP still relies heavily on the evidence base from older studies. These used mainly motor scales, largely inadequate to establish the true functional effectiveness of intervention. Data on comparative proportions of responders actually attaining a minimum clinically-relevant level of amelioration on these scales is lacking. Although helpful, meta-analyses focusing on the primary outcome measures, as used, are therefore limited by these factors and when an attempt was made to convert these to a single scale such as the mRS, the latter was itself limited by its lack of detail and its inadequacy for measuring the small but clinically important changes that may occur in CIDP [42]. 
More recent studies have essentially used scales initially derived nearly twenty years ago. The INCAT, ODSS, ONLS have been widely criticised. Main reasons include failure to correctly detect activity limitations due to proximal arm weakness or fatigue, substantial individual item weighting and poor sensitivity for minor changes. The I-RODS was derived and validated as a new clinically appropriate scale for CIDP research. However, of the six studies we here considered conducted after the I-RODS was published in 2011, none utilised it as primary outcome and only one included it as secondary outcome. Of the 6 , five used the INCAT/ODSS/ONLS, and one, isokinetic dynamometry. MRC sum scores were included as secondary outcomes by all, and always in the original form, with the new MRC grading system proposed [11], never in effect, implemented. There consequently appears to remain a persistent gap between, on the one hand, research into outcome measures for CIDP and research practice in CIDP RCTs, but also on the other, between the evidence base for treatment of CIDP and monitoring methods in clinical practice, as illustrated by the common implementation of the I-RODS but also the persistent reliance on MRC sum scores, by clinicians.

In the U.K., previous guidelines by the Department of Health for use of IVIg for CIDP have advised use of different outcome measures including MRC sum score, ONLS and even INCAT Sensory Sum Score [43]. The issue of scale appropriateness was not considered, nor that of clinically meaningful improvement, leaving to the discretion of clinicians to decide the cut-offs to define response and precise timing as well as scale choice for such a response to be deemed present.

Clinical management and monitoring of patients with CIDP remain a challenge, with many uncertainties due to methods used as well as interpretation of findings. There are notable discrepancies between how the treatments have been found effective in research studies and how clinical care is monitored and difficulties are compounded by the lack of attention paid 
to patient-perceived meaningfulness of detected change. Newer attempts at devising diseasespecific scales are being attempted, some such as the Rasch-informed CAPPRI (Chronic Acquired Polyneuropathy Patient Reported Index) published and validated in different CIDP populations METTRE REF Gwathmey et Bjelica ICI !. How useful such novel patientreported outcome measures may prove in evaluating change is unknown and therefore, so is their usefulness in a research setting ENLEVER REF ICI ! [39,40]. Given the availability issues as well as high cost of IVIg treatment of CIDP and the non-negligible side-effect risk, the question of objective and relevant monitoring methods is paramount. The absence of adequate biomarkers in CIDP and the undeniable placebo treatment effects and psychological aspects of the disease, make it imperative that future research focuses on the pragmatic aspects of clinical monitoring.

\section{References}

1. Breiner A, Barnett C, Bril V. Incat disability score: A critical analysis of its measurement properties. Muscle Nerve [Internet]. 50(2), 164-169 (2014). Available from: http://www.ncbi.nlm.nih.gov/pubmed/24723454.

2. Anon. Aids to the investigation of peripheral nerve injuries. J. Neurol. Psychiatry [Internet]. $\quad 6(1-2), \quad 81 \quad$ (1943). Available from: https://www.ncbi.nlm.nih.gov/pmc/articles/PMC1090046/?page=1.

3. Vanhoutte EK, Faber CG, van Nes SI, et al. Modifying the Medical Research Council 
grading system through Rasch analyses. Brain [Internet]. 135(5), 1639-1649 (2012). Available from: http://www.ncbi.nlm.nih.gov/pubmed/22189568.

4. Dyck PJ, Turner DW, Davies JL, et al. Electronic case-report forms of symptoms and impairments of peripheral neuropathy. Can. J. Neurol. Sci. [Internet]. 29(3), 258-66 (2002). Available from: http://www.ncbi.nlm.nih.gov/pubmed/12195616.

5. Rankin J. Cerebral Vascular Accidents in Patients over the Age of 60: I. General Considerations. Scott. Med. J. [Internet]. 2(4), 127-136 (1957). Available from: http://www.ncbi.nlm.nih.gov/pubmed/13432825.

6. Hughes RA, Newsom-Davis JM, Perkin GD, Pierce JM. Controlled trial prednisolone in acute polyneuropathy. Lancet (London, England) [Internet]. 2(8093), 750-3 (1978). Available from: http://www.ncbi.nlm.nih.gov/pubmed/80682.

7. Sharrack B, Hughes RA. The Guy's Neurological Disability Scale (GNDS): a new disability measure for multiple sclerosis. Mult. Scler. J. [Internet]. 5(4), 223-233 (1999). Available from: http://www.ncbi.nlm.nih.gov/pubmed/10467380.

8. Merkies ISJ, Schmitz PIM, van der Meché FGA, Samijn JPA, van Doorn PA, Inflammatory Neuropathy Cause and Treatment (INCAT) group. Clinimetric evaluation of a new overall disability scale in immune mediated polyneuropathies. $J$. Neurol. Neurosurg. Psychiatry [Internet]. 72(5), 596-601 (2002). Available from: http://www.ncbi.nlm.nih.gov/pubmed/11971045.

9. Merkies IS, Schmitz PI, van der Meché FG, van Doorn PA. Psychometric evaluation of a new sensory scale in immune-mediated polyneuropathies. Inflammatory Neuropathy Cause and Treatment (INCAT) Group. Neurology [Internet]. 54(4), 943-9 (2000). Available from: http://www.ncbi.nlm.nih.gov/pubmed/10690990. 
10. Graham RC, Hughes RAC. A modified peripheral neuropathy scale: the Overall Neuropathy Limitations Scale. J. Neurol. Neurosurg. Psychiatry [Internet]. 77(8), 973-6 (2006). Available from: http://www.pubmedcentral.nih.gov/articlerender.fcgi?artid=2077620\&tool=pmcentrez \&rendertype $=$ abstract.

11. van Nes SI, Vanhoutte EK, van Doorn PA, et al. Rasch-built Overall Disability Scale (R-ODS) for immune-mediated peripheral neuropathies. Neurology [Internet]. 76(4), 337-45 (2011). Available from: http://www.ncbi.nlm.nih.gov/pubmed/21263135.

12. Rajabally YA, Narasimhan M. Jamar hand-held grip dynamometry in chronic inflammatory demyelinating polyneuropathy. J. Neurol. Sci. [Internet]. 325(1-2), 3638 (2013).

Available from: https://linkinghub.elsevier.com/retrieve/pii/S0022510X12005977.

13. Draak THP, Pruppers MHJ, van Nes SI, et al. Grip strength comparison in immunemediated neuropathies: Vigorimeter vs. Jamar. J. Peripher. Nerv. Syst. [Internet]. 20(3), 269-276 (2015). Available from: http://doi.wiley.com/10.1111/jns. 12126.

14. Harbo T, Markvardsen LK, Hellfritzsch MB, Severinsen K, Nielsen JF, Andersen H. NEUROMUSCULAR ELECTRICAL STIMULATION IN EARLY REHABILITATION OF GUILLAIN-BARRÉ SYNDROME: A PILOT STUDY. Muscle Nerve [Internet]. 59(4), mus.26396 (2018). Available from: http://www.ncbi.nlm.nih.gov/pubmed/30549053.

15. Dyck PJ, Litchy WJ, Kratz KM, et al. A plasma exchange versus immune globulin infusion trial in chronic inflammatory demyelinating polyradiculoneuropathy. Ann. Neurol. [Internet]. 36(6), 838-845 (1994). Available from: http://www.ncbi.nlm.nih.gov/pubmed/7998769. 
16. Hahn AF, Bolton CF, Zochodne D, Feasby TE. Intravenous immunoglobulin treatment in chronic inflammatory demyelinating polyneuropathy. A double-blind, placebocontrolled, cross-over study. Brain [Internet]. 119 ( Pt 4), 1067-77 (1996). Available from: http://www.ncbi.nlm.nih.gov/pubmed/8813271.

17. Mendell JR, Barohn RJ, Freimer ML, et al. Randomized controlled trial of IVIg in untreated chronic inflammatory demyelinating polyradiculoneuropathy. Neurology [Internet]. 56(4), 445-9 (2001). Available from: http://www.ncbi.nlm.nih.gov/pubmed/11222785.

18. Vermeulen M, van Doorn PA, Brand A, Strengers PF, Jennekens FG, Busch HF. Intravenous immunoglobulin treatment in patients with chronic inflammatory demyelinating polyneuropathy: a double blind, placebo controlled study. J. Neurol. Neurosurg. Psychiatry [Internet]. 56(1), 36-9 (1993). Available from: http://www.ncbi.nlm.nih.gov/pubmed/8429321.

19. Thompson N, Choudhary P, Hughes RA, Quinlivan RM. A novel trial design to study the effect of intravenous immunoglobulin in chronic inflammatory demyelinating polyradiculoneuropathy. J. Neurol. [Internet]. 243(3), 280-5 (1996). Available from: http://www.ncbi.nlm.nih.gov/pubmed/8936360.

20. Hughes R, Bensa S, Willison $\mathrm{H}$, et al. Randomized controlled trial of intravenous immunoglobulin versus oral prednisolone in chronic inflammatory demyelinating polyradiculoneuropathy. Ann. Neurol. [Internet]. 50(2), 195-201 (2001). Available from: http://www.ncbi.nlm.nih.gov/pubmed/11506402.

21. Hughes RA, Donofrio P, Bril V, et al. Intravenous immune globulin (10\% caprylatechromatography purified) for the treatment of chronic inflammatory demyelinating polyradiculoneuropathy (ICE study): a randomised placebo-controlled trial. Lancet 
Neurol. [Internet]. 7(2), 136-144 (2008). Available from: http://www.ncbi.nlm.nih.gov/pubmed/18178525.

22. RMC Trial Group. Randomised controlled trial of methotrexate for chronic inflammatory demyelinating polyradiculoneuropathy (RMC trial): a pilot, multicentre study. Lancet Neurol. [Internet]. 8(2), 158-164 (2009). Available from: http://www.ncbi.nlm.nih.gov/pubmed/19136303.

23. Kuitwaard K, van den Berg LH, Vermeulen M, et al. Randomised controlled trial comparing two different intravenous immunoglobulins in chronic inflammatory demyelinating polyradiculoneuropathy. J. Neurol. Neurosurg. Psychiatry [Internet]. 81(12), 1374-1379 (2010). Available $\quad$ from: http://www.ncbi.nlm.nih.gov/pubmed/20587484.

24. Nobile-Orazio E, Cocito D, Jann S, et al. Intravenous immunoglobulin versus intravenous methylprednisolone for chronic inflammatory demyelinating polyradiculoneuropathy: a randomised controlled trial. Lancet Neurol. [Internet]. 11(6), 493-502 (2012). Available from: http://www.ncbi.nlm.nih.gov/pubmed/22578914.

25. Camdessanche J-P, Ferraud K, Lagrange E, et al. Multicentre, Randomised, OpenLabel Trial To Compare Efficacy And Tolerance Of Prednisone And IVIG In Patients With CIDP On A One Year Follow Up (P7.092). Neurology. 82(10 Supplement) (2014).

26. Markvardsen LH, Harbo T. Subcutaneous immunoglobulin treatment in CIDP and MMN. Efficacy, treatment satisfaction and costs. J. Neurol. Sci. [Internet]. 378, 19-25 (2017). Available from: http://www.ncbi.nlm.nih.gov/pubmed/28566163.

27. Kuwabara S, Mori M, Misawa S, et al. Intravenous immunoglobulin for maintenance treatment of chronic inflammatory demyelinating polyneuropathy: a multicentre, open- 
label, 52-week phase III trial. J. Neurol. Neurosurg. Psychiatry [Internet]. 88(10), 832-838 (2017). Available from: http://www.ncbi.nlm.nih.gov/pubmed/28768822.

28. van Schaik IN, Bril V, van Geloven N, et al. Subcutaneous immunoglobulin for maintenance treatment in chronic inflammatory demyelinating polyneuropathy (PATH): a randomised, double-blind, placebo-controlled, phase 3 trial. Lancet Neurol. [Internet]. 17(1), 35-46 (2018). Available from: http://www.ncbi.nlm.nih.gov/pubmed/29122523.

29. Dyck PJ, O’Brien PC, Oviatt KF, et al. Prednisone improves chronic inflammatory demyelinating polyradiculoneuropathy more than no treatment. Ann. Neurol. [Internet]. 11(2), 136-141 (1982). Available from: http://www.ncbi.nlm.nih.gov/pubmed/7041788.

30. van Schaik IN, Eftimov F, van Doorn PA, et al. Pulsed high-dose dexamethasone versus standard prednisolone treatment for chronic inflammatory demyelinating polyradiculoneuropathy (PREDICT study): a double-blind, randomised, controlled trial. Lancet Neurol. [Internet]. 9(3), 245-253 (2010). Available from: https://linkinghub.elsevier.com/retrieve/pii/S1474442210700211.

31. Dyck PJ, Daube J, O'Brien $\mathrm{P}$, et al. Plasma Exchange in Chronic Inflammatory Demyelinating Polyradiculoneuropathy. N. Engl. J. Med. [Internet]. 314(8), 461-465 (1986). Available from: http://www.nejm.org/doi/abs/10.1056/NEJM198602203140801.

32. Hahn AF, Bolton CF, Pillay $\mathrm{N}$, et al. Plasma-exchange therapy in chronic inflammatory demyelinating polyneuropathy. A double-blind, sham-controlled, crossover study. Brain [Internet]. 119 ( $\mathrm{Pt} 4$ ), 1055-66 (1996). Available from: http://www.ncbi.nlm.nih.gov/pubmed/8813270. 
33. Rai SK, Yazdany J, Fortin PR, Aviña-Zubieta JA. Approaches for estimating minimal clinically important differences in systemic lupus erythematosus. Arthritis Res. Ther. [Internet]. $17(1), \quad 143 \quad$ (2015). Available from: http://www.ncbi.nlm.nih.gov/pubmed/26036334.

34. Jaeschke R, Singer J, Guyatt GH. Measurement of health status. Ascertaining the minimal clinically important difference. Control. Clin. Trials [Internet]. 10(4), 407-15 (1989). Available from: http://www.ncbi.nlm.nih.gov/pubmed/2691207.

35. Engel L, Beaton DE, Touma Z. Minimal Clinically Important Difference. Rheum. Dis. Clin. North Am. [Internet]. 44(2), 177-188 (2018). Available from: http://www.ncbi.nlm.nih.gov/pubmed/29622290.

36. Eftimov F, Vermeulen M, van Doorn PA, Brusse E, van Schaik IN. Long-term remission of CIDP after pulsed dexamethasone or short-term prednisolone treatment. Neurology [Internet]. 78(14), 1079-1084 (2012). Available from: http://www.neurology.org/cgi/doi/10.1212/WNL.0b013e31824e8f84.

37. Merkies ISJ, van Nes SI, Hanna K, Hughes RAC, Deng C. Confirming the efficacy of intravenous immunoglobulin in CIDP through minimum clinically important differences: shifting from statistical significance to clinical relevance. J. Neurol. Neurosurg. Psychiatry [Internet]. 81(11), 1194-1199 (2010). Available from: http://www.ncbi.nlm.nih.gov/pubmed/20647554.

38. Spina E, Topa A, Iodice $\mathrm{R}$, et al. Six-minute walk test is reliable and sensitive in detecting response to therapy in CIDP. J. Neurol. [Internet]. 266(4), 860-865 (2019). Available from: http://link.springer.com/10.1007/s00415-019-09207-1.

39. Bjelica B, Peric S, Gwathmey K, et al. Chronic Acquired Polyneuropathy Patient Reported Index (CAPPRI) in chronic inflammatory demyelinating 
polyradiculoneuropathy. J. Peripher. Nerv. Syst. [Internet]. , jns.12329 (2019). Available from: http://www.ncbi.nlm.nih.gov/pubmed/31209940.

40. Gwathmey KG, Sadjadi R, Horton WB, et al. Validation of a simple disease-specific, quality-of-life measure for diabetic polyneuropathy. Neurology [Internet]. 90(23), e2034-e2041 (2018). Available from: http://www.neurology.org/lookup/doi/10.1212/WNL.0000000000005643.

41. Fukumori N, Yamamoto Y, Takegami M, et al. Association between hand-grip strength and depressive symptoms: Locomotive Syndrome and Health Outcomes in Aizu Cohort Study (LOHAS). Age Ageing [Internet]. 44(4), 592-598 (2015). Available from: http://www.ncbi.nlm.nih.gov/pubmed/25712514.

42. Eftimov F, Winer JB, Vermeulen M, de Haan R, van Schaik IN. Intravenous immunoglobulin for chronic inflammatory demyelinating polyradiculoneuropathy [Internet]. In: Cochrane Database of Systematic Reviews. van Schaik IN (Ed.), John Wiley \& Sons, Ltd, Chichester, UK, CD001797 (2009) [cited 2019 Apr 20]. Available from: http://www.ncbi.nlm.nih.gov/pubmed/19160200.

43. Wimperis J, Lunn M, Jones A, et al. Clinical guidelines for immunoglobulin use. Second edition update [Internet]. (2011). Available from: https://www.gov.uk/government/uploads/system/uploads/attachment_data/file/216671/ dh_131107.pdf.

Table 1. Summary of Outcome Measures used in principal RCTs considered in current $\underline{\text { analysis }}$

\begin{tabular}{|l|l|l|}
\hline Author, year & Intervention & Scale \\
\hline Dyck, 1994 [15] & IVIg to PLEX & Neuropathy disability score (NDS) \\
\hline
\end{tabular}




\begin{tabular}{|c|c|c|}
\hline Hahn, 1996 [16] & IVIg to placebo & Neuropathy disability score (NDS) \\
\hline Mendell, 2001 [17] & IVIg to placebo & $\begin{array}{l}\text { Hughes Disability Scale (HDS) as primary outcome measure } \\
\text { and the Average Muscle Score (HMAS), as secondary } \\
\text { outcome }\end{array}$ \\
\hline $\begin{array}{l}\text { Vermeulen, } 1993 \\
\text { [18] }\end{array}$ & IVIg to placebo & $\begin{array}{l}\text { Rankin scale as primary and the MRC sum score as } \\
\text { secondary outcome measure }\end{array}$ \\
\hline $\begin{array}{l}\text { Thompson, } 1996 \\
{[19]}\end{array}$ & IVIg to placebo & $\begin{array}{l}\text { Hammersmith Motor Ability Scale (HMAS) as primary } \\
\text { outcome and secondary outcomes including } 10 \text { metre } \\
\text { walking time, MRC sum score, myometry and 9-hole peg } \\
\text { test }\end{array}$ \\
\hline Hughes, 2001 [20] & IVIg to prednisolone & $\begin{array}{l}\text { INCAT scale as primary outcome and } 10 \text { metre walking time, } \\
\text { MRC sum score, grip strength, 9-hole peg test, Rankin scale } \\
\text { and Rotterdam Handicap Scale as secondary outcomes }\end{array}$ \\
\hline $\begin{array}{l}\text { The ICE Study, } \\
2008[21]\end{array}$ & IVIg to placebo & $\begin{array}{l}\text { INCAT scale as primary outcome and grip strength as } \\
\text { secondary outcome }\end{array}$ \\
\hline $\begin{array}{l}\text { RMC Trial Group, } \\
2009 \text { [22] }\end{array}$ & $\begin{array}{l}\text { Usefulness of } \\
\text { methotrexate } \quad \text { in } \\
\text { reducing IVIG or steroid } \\
\text { requirements }\end{array}$ & ONLS \\
\hline $\begin{array}{l}\text { Kuitwaard et al., } \\
2010[23]\end{array}$ & $\begin{array}{l}\text { Comparing } 2 \text { different } \\
\text { IVIg products }\end{array}$ & $\begin{array}{l}\text { ODSS as primary outcome with MRC sum score and grip } \\
\text { strength as secondary clinical outcomes }\end{array}$ \\
\hline $\begin{array}{l}\text { Nobile-Orazio et } \\
\text { al., } 2012 \text { [24] }\end{array}$ & $\begin{array}{l}\text { IVIg to intravenous } \\
\text { methylprednisolone }\end{array}$ & ONLS and $\mathrm{mRS}$ scores \\
\hline $\begin{array}{l}\text { Markvardsen \& } \\
\text { Harbo, } 2017[26]\end{array}$ & $\begin{array}{l}\text { Subcutaneous } \\
\text { immunoglobulin to IVIg }\end{array}$ & $\begin{array}{l}\text { Isokinetic dynamometry as primary outcome measure and } \\
\text { MRC sum score, Jamar grip dynamometry, 9-hole peg test, } \\
40 \text { metre walk test and ODSS as secondary outcomes }\end{array}$ \\
\hline $\begin{array}{l}\text { Kuwabara et al., } \\
2017 \text { [27] }\end{array}$ & $\begin{array}{l}\text { An open-label Japanese } \\
52 \text {-week phase III trial } \\
\text { prescribing IVIG }\end{array}$ & adjusted INCAT scale \\
\hline $\begin{array}{l}\text { van Schaik et al., } \\
2018[28]\end{array}$ & $\begin{array}{l}2 \text { SCIg dosages versus } \\
\text { placebo }\end{array}$ & $\begin{array}{l}\text { adjusted INCAT as primary outcome, and grip strength, } \\
\text { MRC sum score and I-RODS as secondary outcome }\end{array}$ \\
\hline Dyck, 1982 [29] & $\begin{array}{l}\text { Steroids were compared } \\
\text { to placebo }\end{array}$ & Neurological impairment scale (NIS) \\
\hline $\begin{array}{l}\text { van Schaik, } 2010 \\
{[30]}\end{array}$ & $\begin{array}{l}\text { Daily versus monthly } \\
\text { high-dose steroids }\end{array}$ & Rivermead Mobility Index and the INCAT disability scale \\
\hline Dyck, 1986 [31] & $\begin{array}{lll}\text { PLEX } & \text { versus } & \text { sham } \\
\text { PLEX } & \end{array}$ & Neurological impairment scale (NIS) \\
\hline $\begin{array}{l}\text { Hahn, Bolton, } \\
\text { Pillay, } 1996 \text { [32] }\end{array}$ & $\begin{array}{lll}\text { PLEX } & \text { versus sham } \\
\text { PLEX } & & \end{array}$ & Neurological impairment scale (NIS) \\
\hline $\begin{array}{l}\text { Camdessanche, } \\
2014[25] .\end{array}$ & $\begin{array}{l}\text { IVIg to } \quad \text { oral } \\
\text { prednisolone }\end{array}$ & INCAT \\
\hline
\end{tabular}

Table 2. Outcome Measures used in CIDP research 1990-2019. 


\begin{tabular}{|c|c|}
\hline Outcome Measure & Type \\
\hline MRC Sum Score & Classical Motor Scale \\
\hline Average Muscle Score (AMS) & Classical Motor Scale \\
\hline Grip Strength (Martin or Jamar) & Quantitative Motor Scale \\
\hline Myometry & Quantitative Motor Scale \\
\hline Ten metre timed walk & Task-specific disability scale \\
\hline Forty metre walk test & Task-specific disability scale \\
\hline Six-minute walk & Task-specific disability scale \\
\hline Rivermead Mobility Index (RMI) & Task-specific disability scale \\
\hline Nine-hole peg test & Upper limb-specific disability scale \\
\hline Hughes Disability Scale (HDS) & Disability Scale \\
\hline $\begin{array}{l}\text { Neuropathy Impairment Scale (NIS); } \\
\text { Neuropathy Disability Scale (NDS) }\end{array}$ & Disability Scale \\
\hline Hammersmith Motor Ability Scale (HMAS) & Disability Scale \\
\hline Modified Rankin scale (mRS) & Disability Scale \\
\hline Rotterdam Handicap Scale (RHS) & Disability Scale \\
\hline $\begin{array}{l}\text { Inflammatory Neuropathy Cause and Treatment } \\
\text { (INCAT) Scale }\end{array}$ & Disability Scale \\
\hline Overall Disease Disability Scale (ODSS) & Disability Scale \\
\hline Overall Neuropathy Limitation Score (ONLS) & Disability Scale \\
\hline $\begin{array}{l}\text { Inflammatory Rash-built Overall Disability } \\
\text { Scale (I-RODS) }\end{array}$ & Patient Reported Outcome Measure \\
\hline $\begin{array}{l}\text { Chronic Acquired Polyneuropathy Patient } \\
\text { Reported Index (CAPPRI) }\end{array}$ & Patient Reported Outcome Measure \\
\hline
\end{tabular}

